\title{
Designing Educational Game to Increase Environmental Awareness
}

\author{
https://doi.org/10.3991/ijet.v16i15.22661 \\ Sheila Nurul Huda $(\bowtie)$, M. Fadillah Ramadhan \\ Universitas Islam Indonesia, Yogyakarta, Indonesia \\ sheila@uii.ac.id
}

\begin{abstract}
Plastic is a versatile material that is inexpensive and has the characteristics of being lightweight, strong, durable, anti-corrosive, with high thermal and electrical insulation properties. Regardless of the positive impact on economic development, it brings negative impacts on the environment. The amount of plastic waste, that continues to increase, pollutes the environment and ocean chronically. There needs to be a change in people behavior and awareness to reduce the use of it. In fact, raising awareness of the environment from the dangers of plastic waste is not an easy matter, but if taught since childhood, good environmental awareness and habits will be formed. This research tried to raise awareness among elementary school children in Indonesia of the dangers of plastic waste through an educational game developed using the Game Development Life Cycle (GDLC). GDLC consists of six phases: initiation, pre-production, production, testing, beta, and release. Strategy genre was chosen for engaging gameplay. Environmental awareness and knowledge on the danger of plastic waste were given integrally through storylines, gameplay, goals, and animated cutscenes. The results of testing at the beta stage on the respondents showed that $71.11 \%$ of primary school student respondents gained environmental knowledge.
\end{abstract}

Keywords-Game Development Life Cycle, strategy game, educational game, plastic waste, environmental awareness

\section{Introduction}

Plastic is a material that is very closely related to human life today. Plastics are used in various areas of life because of their durable properties and low price. The term plastic is the general name given to a synthetic polymer material. Bakelite is the first fully synthetic polymer, introduced by Belgian chemist, Leo Baekeland in 1907, and patented in 1909 [1]. After Bakelite, research on plastics grew rapidly over the next few decades. Until now, there are more than 20 plastic groups, each of which has different levels of quality and variety [2]. Plastics were created to answer market needs for increasingly scarce and expensive items such as ivory and silk [3].

The mass production of plastics for everyday life began in the 1940s and 1950s, which was also driven by World War II [4]. Plastic is a versatile material that is inex- 
pensive and has the characteristics of being lightweight, strong, durable, anticorrosive, with high thermal and electrical insulation properties. The large number of polymer variants and their versatile properties allows plastics to be applied in various fields. In fact, at a time when the global production of plastic was less than a million tons per annum, Yarsley \& Couzen [5] predicted that the use of plastic would be inexhaustible. The development of plastic technology with its various properties enables massive plastic production which brings in many benefits, in terms of technological developments, energy savings, and various other social benefits [6].

The existence of plastic then creates conditions that allow mass consumption and global trade [7]. For example, plastic packaging allows new means of handling and distributing commodities. It is not an exaggeration to say that capitalism grows with plastic as its fuel. In 2012 it was noted that 280 million tons of plastics were produced worldwide, with a projected increase to 33 billion tons annually by 2050 [8]. The most prevalent use of plastics today, which is about more than one third of plastic production, is disposable items of packaging, most of which are discarded within about one year after production [9].

Regardless of the fact that plastic has a positive impact on economic development, this cheap and durable material also brings a negative impact on the environment. Since plastic is inexpensive, people do not hesitate to immediately throw away used plastic. Unfortunately, its durable nature makes this material take a long time to be biodegraded. Plastic takes about $10 \%$ of waste composition we generate, and most of it ends up in landfills [10]. Plastic waste that is disposed inappropriately can pollute the environment and cause problems such as flooding. Drains can be clogged by plastic waste dumped into rivers.

Bad waste management practices and irresponsible human behavior have caused a large amount of plastic waste polluting the environment and end up polluting the Oceans. Environmental problems caused by plastic waste that has polluted global Oceans and seas have reached a chronic level [11]. The effect of UV radiation allows plastics, which are actually nonbiodegradable, to be degraded into small fragments, called as microplastics. It is estimated that 200,000 microplastics per $\mathrm{km} 2$ of the ocean's surface commonly exist [12]. More than 267 species in the marine environment have been affected by plastic waste in the form of plastic entanglement or ingestion. Turtles, for example, are often found eating plastic which they think of as jellyfish. Not to mention the fact that microplastics are easily inhaled and swallowed by sea creatures. If humans eat marine animals that contain microplastics, they might have health problem, including nervous system, hormone and immunity problems, as well as increased risk of cancer.

In Indonesia, plastic waste management is still poor. Indonesia is in the second position of the top 20 countries that have the worst plastic waste management with an amount of 3.22 million tons / year and 0.48-1.29 million tons / year polluting the oceans [13]. With such a huge amount of plastic waste, disposing trash properly is not enough. There needs to be a change in behavior and awareness to reduce the use of plastic in order to reduce the level of plastic waste. Unfortunately, raising awareness of the environment from the dangers of plastic waste is not an easy matter, but if taught since childhood, good environmental awareness and habits will be formed. 
Research using educational games has been done a lot and has proven that education through games provides positive benefits for children. As an example, Triyanto \& Supriyono [14] mentioned that educational games can increase knowledge about environmental cleanliness and help recognize the types of waste in grade 1 elementary school children. In other domain, several researchers gave positive results on the employment of educational game. Baig \& Alotaibi [15] found positive result on students' performance based on their score average in standard tests using video games based on Mathematics curriculum. In learning EFL Grammar and Vocabulary, CastilloCuesta [16] also gave positive impact from digital games to improve learners' grammar and their vocabulary knowledge. Video game was also able to increase students' awareness of Santa Cruz's sculptural heritage [17]. Therefore, this research tried to raise the awareness among elementary school children in Indonesia of the dangers of plastic waste through an educational game developed using the Game Development Life Cycle.

\section{Methods}

Game is a software with the aim of providing entertainment. According to Adams [18], game is a type of play activity, conducted in the context of a pretended reality, in which the participant (s) try to achieve at least one arbitrary, nontrivial goal by acting in accordance with rules. The two key elements in the game by that definition are goals and rules. Kanode \& Haddad [19] emphasized the element of fun as the main element of a successful game. In practice, game development that only adopts an approach of the software development life cycle (SDLC) is not enough, this approach does not meet the needs because developers face several challenges during its cycle. To solve this problem, game development uses a specific approach called the game development life cycle (GDLC) [20]. GDLC has six development phases: Initiation, Pre-Production, Production, Testing, Beta, and Release, as shown in Figure 1.

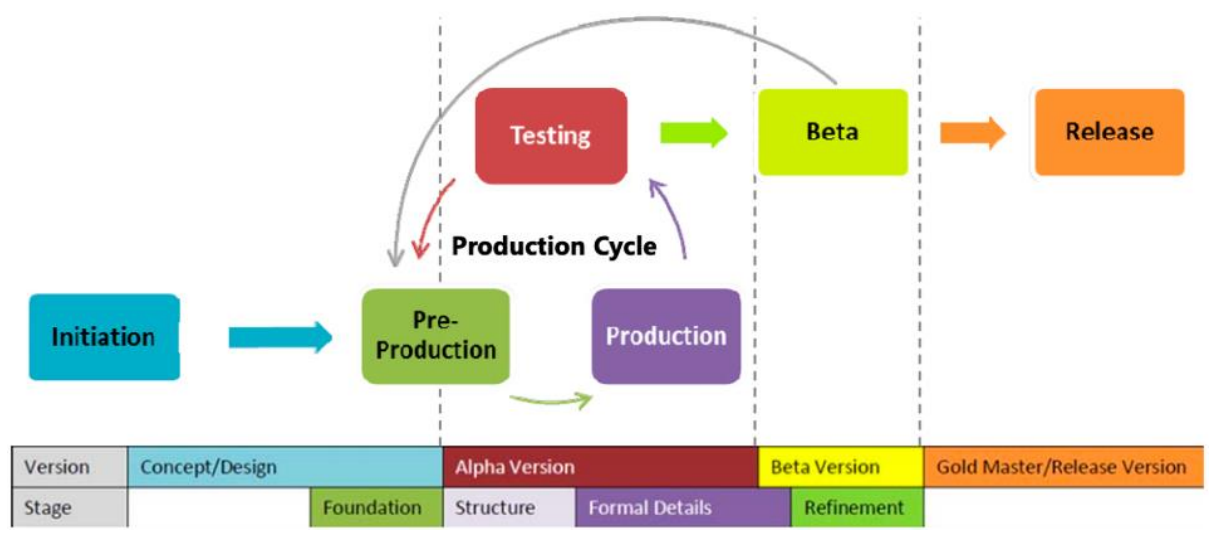

Fig. 1. Game Development Life Cycle (GDLC) consists of 6 development phases [20] 
Initiation is a phase to create a game concept and a simple game description. In this phase, game developers must analyze what will be built based on the opportunities existing in the community. The pre-production phase is the phase for creating and revising game design, with the output of which is a game design document (GDD) which contains the game genre, gameplay, mechanics, storyline, challenges, and technical aspects of the game. Production is the main stage associated with creating assets, writing program code, and integrating assets and program code into a complete game. The GDLC testing phase is an internal testing done by developers to test game usability and playability. Beta is the testing phase carried out by an external tester, also known as a beta tester. In choosing a beta tester, two methods can be used, namely closed beta and open beta. The closed beta is a test conducted by invited individuals, while the open beta allows anyone to register as a participant.

\section{$3 \quad$ Findings \& Discussion}

\subsection{Initiation}

The initiation phase is the phase for identifying the initial idea and concept of the game. Based on the Jakarta Environmental Agency and the Indonesian Plastic Bag Diet Movement, Jakarta residents use around 5.2-6.5 tons of plastic bags per day and generate around 978 tons of plastic waste per day. Even though Indonesia has implemented disincentives for the use of plastic bags in retail minimarkets, the reality is that the use of single-use plastic bags is still high. Apart from plastic bags, one of the plastic wastes that is often encountered is a plastic straw. The use of plastic straws in Indonesia if all collected will have a length of $16,784 \mathrm{~km}$ which is equivalent to the distance from Jakarta to Mexico City. Other than that, according to the Indonesian Ministry of Environment and Forestry, every year Indonesia consumes 4.82 billion plastic bottles which instantly become garbage. From this problem, the educational game to be built focused on waste from plastic bag, plastic straws, and single-use plastic bottles that are currently still being used massively by the people.

Messages to be conveyed through the game include:

1. Disaster impact of plastic waste: flooding and pollution of marine ecosystems.

2. Campaign to reduce the use of disposable plastic bags and replace them with cloth bags that can be used repeatedly.

3. Campaign to reduce the use of plastic straws.

4. Campaign to reduce the use of disposable plastic bottles by bringing your own drinks in reusable drinking bottles.

We also interviewed the headmaster of one selected elementary school in Indonesia, Generasi Azkia Elementary School, located in Bogor, Indonesia, to get a better picture about elementary school students. Interviews were conducted on 11 September 2020 and 19 October 2020. The results of these interviews indicated problems and opportunities, such as: 
1. The occurrence of the COVID 19 pandemic which caused the teaching and learning process to be shifted to online learning.

2. During the online learning process, students were more interested in fun learning methods such as animation than reading books.

3. Schools never used games as a learning medium.

4. General material regarding the environment had been taught, but not specifically regarding plastic waste.

5. The majority of students knew and were proficient at using devices and playing games.

6. Because students studied at home, the game had to be accessible online and at least could be played on a smart phone device.

7. The principal suggested that the game should target users who were at least grade 4 students. At that age, a child has started to become independent and understand some things enough without the help from others.

In terms of the game genre, the strategy genre was chosen for several reasons. The strategy game genre is a video game genre that emphasizes skillful thinking and planning to achieve victory. A player must plan a series of actions against one or more opponents to reduce enemy troops which is usually the goal of the game [21]. Tower Defense is a subgenre of strategy video games where the objective is to defend a player's territory or possession by deterring enemy attackers, usually achieved by placing defensive structures in or along their path of attack. Strategy games are able to provide a fun gameplay while sharpening the brain to think about winning strategies, and potentially increasing engagement in the game. Strategy games can also form user characteristics for critical thinking, thus building a more advanced mindset that can respect all actions taken [22].

\subsection{Pre-Production}

In the pre-production phase, a Game Design Document was created as a result of a deeper analysis of the results of the initiation phase. Some of the main information from the game design document are shown in Table 1.

Table 1. Game Design Document

\begin{tabular}{|l|l|}
\hline Game Title & \multicolumn{1}{|c|}{ Plastic Stream } \\
\hline Number of Player & Single player \\
\hline Target Audience & Grade 4, 5, and 6 Elementary School Students \\
\hline Objectives & $\begin{array}{l}\text { Players must protect a zone by placing a boat team whose task is to collect } \\
\text { plastic waste, to prevent it from reaching that zone. }\end{array}$ \\
\hline $\begin{array}{l}\text { Game Mechanics and } \\
\text { Rules }\end{array}$ & $\begin{array}{l}\text { Players interact by clicking or tapping a button. } \\
\text { Players will manage a boat team that has three color variants with their respec- } \\
\text { tive functions. } \\
\text { The red boat team can collect plastic bag trash, the blue boat team can collect } \\
\text { plastic bottle trash, the yellow boat team can collect plastic straw trash. } \\
\text { Players are asked to complete the objectives. If they fail, they have to start over. } \\
\text { Inside each level, there is a net that can protect the objective, these nets can }\end{array}$ \\
\hline
\end{tabular}




\begin{tabular}{|c|c|}
\hline Game Title & Plastic Stream \\
\hline & $\begin{array}{l}\text { catch the plastic waste that the player has missed three times then after which } \\
\text { the nets will be destroyed. }\end{array}$ \\
\hline Challenge & $\begin{array}{l}\text { The difficulty level will be based on the wave, in which higher wave gives more } \\
\text { difficulty. If the player successfully passes all the waves, then the player suc- } \\
\text { cessfully completes the level and continues to the next level. Each level will } \\
\text { consist of three waves. To provide challenges to players, the game pattern will } \\
\text { also be random, such as where the plastic waste spawns and the number of boat } \\
\text { teams that will be owned. In the second level, there will also be a new chal- } \\
\text { lenge, such as mysterious trash which must be open using special move. }\end{array}$ \\
\hline Constraint & $\begin{array}{l}\text { The game will have two levels plus a tutorial at the start of the game. Each level } \\
\text { describes locations that are affected by plastic waste: city and the sea. The } \\
\text { tutorial will use the same background theme as level } 1 \text {. } \\
\text { Tutorial: Player must watch a game intro cutscene and follow the tutorial in- } \\
\text { structions. After successfully following all the instructions, the player will move } \\
\text { to level } 1 \text {. } \\
\text { Level 1: The player must watch an opening cutscene of level } 1 \text {. The player must } \\
\text { defend a water pump from plastic waste that is carried away in three waves. } \\
\text { After the objective has been achieved, the player must watch the final cutscene } \\
\text { of level 1. } \\
\text { Level 2: The player must watch an opening cutscene of level } 2 \text {. The player must } \\
\text { complete a short tutorial of new challenge, where the player must defend a } \\
\text { garbage transport ship from plastic waste that is drifting in three waves. After } \\
\text { the objective has been achieved, the player will watch the final cutscene of level } \\
2 \text {. }\end{array}$ \\
\hline Storyline & $\begin{array}{l}\text { Tutorial: Cut scene intro shows about the dangers of plastic waste as well as } \\
\text { teaches game mechanics. } \\
\text { Level 1: Cut scene animation will show the dangers of plastic waste, a city } \\
\text { experiencing flooding due to plastic waste in a river flow. A water pump to } \\
\text { pump water into the sea has been turned on, the player must protect the water } \\
\text { pump by placing a plastic garbage collection boat in the river strategically. } \\
\text { Missing trash from the boat can get caught in the nets before it reaches the water } \\
\text { pump. The net will be damaged after catching three missed garbage. Players can } \\
\text { save the city if the net is not damaged by trash. If the player is successful, then } \\
\text { the player has saved the city from flooding. } \\
\text { Level 2: Cutscene animation will show the presence of trash that is carried into } \\
\text { the sea and endangers marine animals. The garbage transport boat is working to } \\
\text { clean the sea. The player must protect the sea by placing the plastic garbage } \\
\text { collection boat in the downstream of the river strategically. Trash that the boat } \\
\text { misses can get caught in the nets before it reaches the open seas. The net will be } \\
\text { damaged if three garbage get into the net. The player can save the ocean if the } \\
\text { net is not damaged by trash. If the player is successful, then the player has saved } \\
\text { the ocean from plastic waste. } \\
\text { Epilogue: The animation presented shows a campaign to protect the environ- } \\
\text { ment by reducing plastic waste such as single-use plastic bags, straws, and } \\
\text { bottles. }\end{array}$ \\
\hline Result & The player will win if s/he completes the objective of each level. \\
\hline
\end{tabular}

\subsection{Production}

Production is the main phase associated with creating assets, writing program code, and integrating assets and program code into a complete game. To build a game "Plastic Stream", variety of assets were needed to form the visualization of the game itself. The assets in this game consisted of the main character, enemies, buttons, back- 
grounds, cutscenes, and supporting objects. All the asset designs were created using Adobe Illustrator software, while some of them were created using Adobe Photoshop. Table 2 shows examples of some of the created assets.

Table 2. Game Asset Design

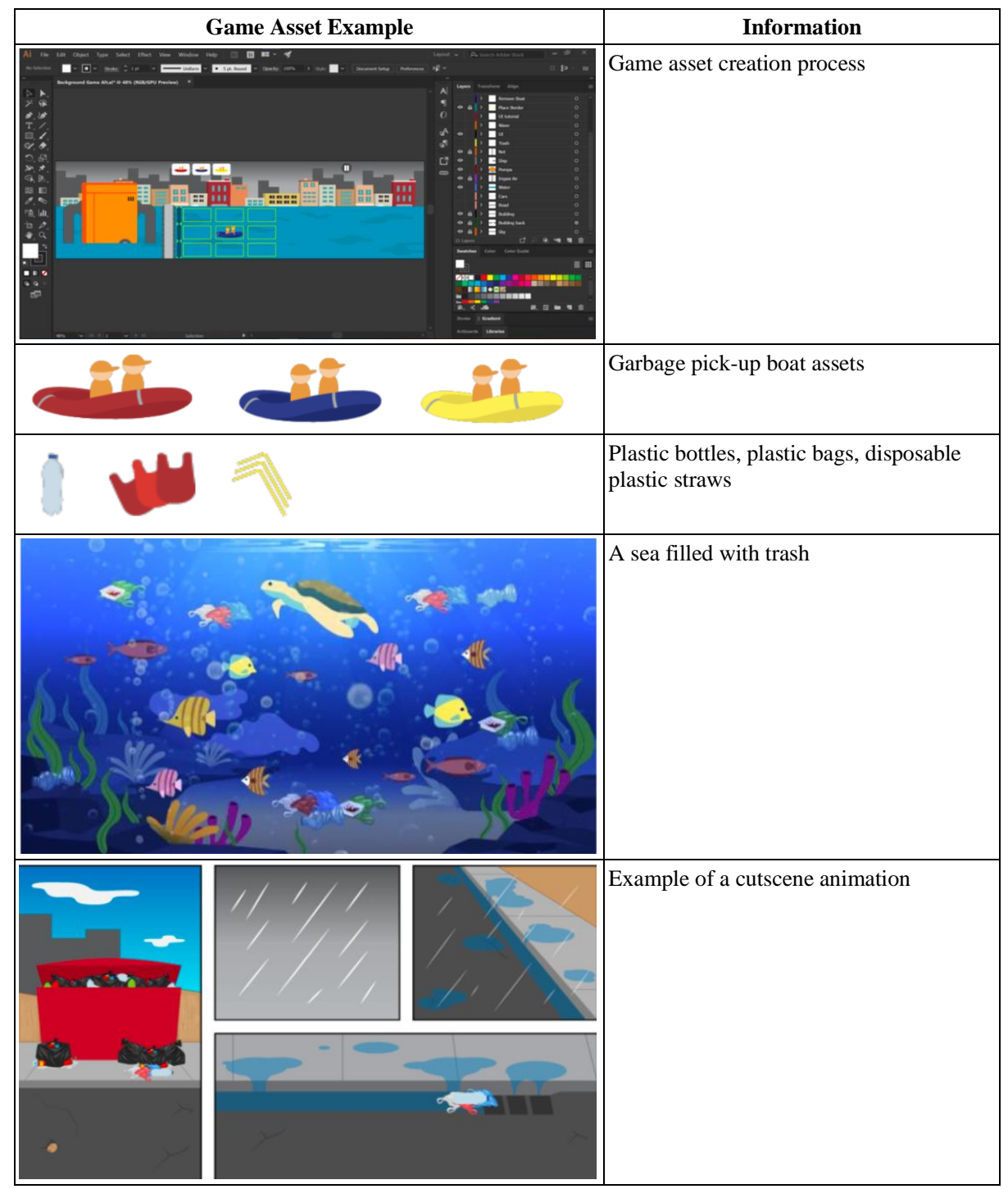

In addition, there were also sound effects of water splashing, sound effects of waves, background music, and others. Then the assets that had been built were used to produce a complete game. The game was developed using the Gdevelop game engine. All the assets that had been created were entered into the game engine to form the 
desired appearance. An example of a game display that had been made is shown in Table 3 .

Table 3. Game Production

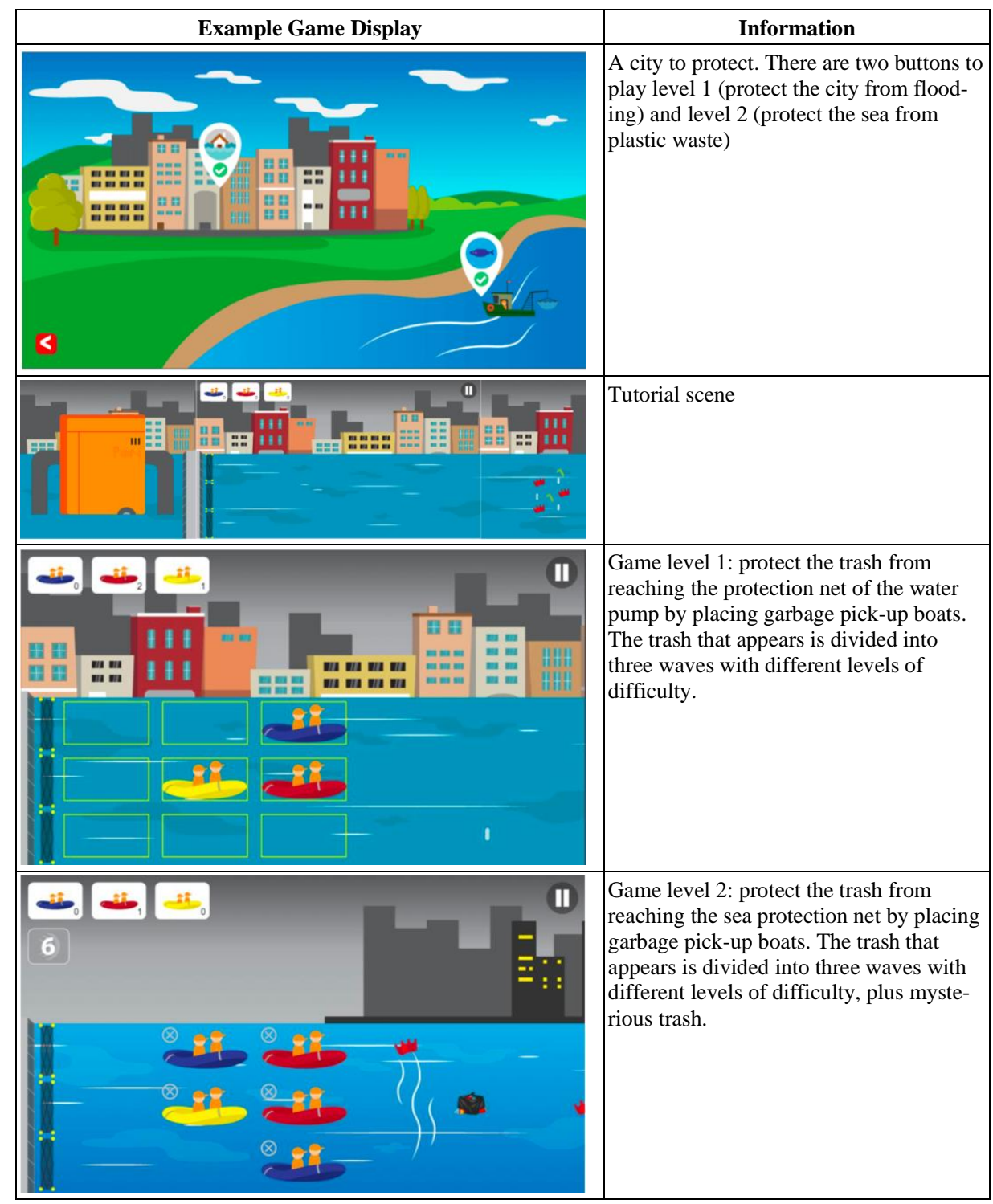

\subsection{Testing}

In the testing phase, the developer tested the game's functionality using black box testing. The black box testing was divided into four categories: black box testing on 
main menu, black box testing on tutorial, black box testing on level 1 , and black box testing on level 2 . The black box test results stated that all the features in each scene had run smoothly.

\subsection{Beta}

This test involved a total of 45 students, from grade 4 to grade 6 students of Generasi Azkia Elementary School. The testing was done in three days, i.e. on 19 November 2020, 23 November 2020, and 24 November 2020. The beta testing used the usability testing and pretest-posttest testing method.

The game testing was carried out using the pretest and posttest methods to measure whether the game can increase the users' knowledge and awareness of plastic waste or not. The questions were about plastic waste, aiming to find out the impact of the game by comparing the knowledge before and after playing the game. The test was designed using a One Group Pretest-Posttest Design as shown in Table 4.

Table 4. One Group Pretest-Posttest Design

\begin{tabular}{|c|c|c|}
\hline Pretest Measurement & Treatment & Posttest Measurement \\
\hline $\begin{array}{l}\text { Measuring student environmental } \\
\text { knowledge and awareness before } \\
\text { playing the game. The students were } \\
\text { given } 10 \text { multiple choice questions. } \\
\text { Every correct answer was given a } \\
\text { score of } 10 \text {, while incorrect answer did } \\
\text { not reduce the score. The highest total } \\
\text { score was } 100 \text {. }\end{array}$ & $\begin{array}{l}\text { Application of the game. } \\
\text { The students played the } \\
\text { game "Plastic Stream". }\end{array}$ & $\begin{array}{l}\text { Measuring student environmental } \\
\text { knowledge and awareness after play- } \\
\text { ing the game. The students were given } \\
10 \text { multiple choice questions. Every } \\
\text { correct answer was given a score of } \\
10 \text {, while incorrect answer did not } \\
\text { reduce the score. The highest total } \\
\text { score was } 100 \text {. }\end{array}$ \\
\hline
\end{tabular}

The test results were grouped into an understanding scale as in Table 5. Then the test results were also used to calculate the gain of knowledge of each respondent based on Hake [23], with the formula shown in Equation 1.

$$
g=\frac{\text { posttest score-pretest score }}{\text { maximum score-pretest score }}
$$

where $\mathrm{g}$ is individual gain of knowledge.

Table 5. Understanding level categorization

\begin{tabular}{|l|l|}
\hline \multicolumn{1}{|c|}{ Score } & \multicolumn{1}{c|}{ Category } \\
\hline $0-20$ & Very poor \\
\hline $21-40$ & Poor \\
\hline $41-60$ & Medium \\
\hline $61-80$ & Good \\
\hline $81-100$ & Very good \\
\hline
\end{tabular}

The knowledge gain category was based on Hake [23], which is shown in Table 6. 
Table 6. Gain interval categorization

\begin{tabular}{|c|c|}
\hline Gain interval $(\mathbf{g})$ & Category \\
\hline$g \geq 0.70$ & High \\
\hline $0.30<g<0.70$ & Medium \\
\hline$g \leq 0.30$ & Low \\
\hline$g=0$ & No gain \\
\hline
\end{tabular}

Comparison between the pretest and posttest results are shown in Figure 2. A total of 11 respondents obtained a gain value of more than 0.7 which could be categorized as high, and their posttest results were in very good understanding level. A total of 15 respondents obtained a gain value between 0.7 and 0.3 which could be categorized as moderate, 11 of which obtained posttest results which fell in the very good understanding level, while the rest had a good understanding level. A total of six respondents obtained a gain value less than or equal to 0.3 which could be categorized as low, but they were in the good understanding level. A total of 13 respondents had no gain value, but 11 of them had a very good understanding level and the rest had a good understanding level. This means that the posttest scores of all the students fell in the good understanding and very good understanding levels. The majority (33 out of 45 students) were in the very good understanding level. The highest gain was found among grade 5 students, followed by grade 4 students and grade 6 students. As many as seven respondents had no gain value. The respondents who did not show a gain value already had a high pretest score between 90-100, so these students already had good environmental knowledge without having to play the game. Based on the results of the above tests, it was found that $71.11 \%$ of the students gained environmental and plastic waste understanding.

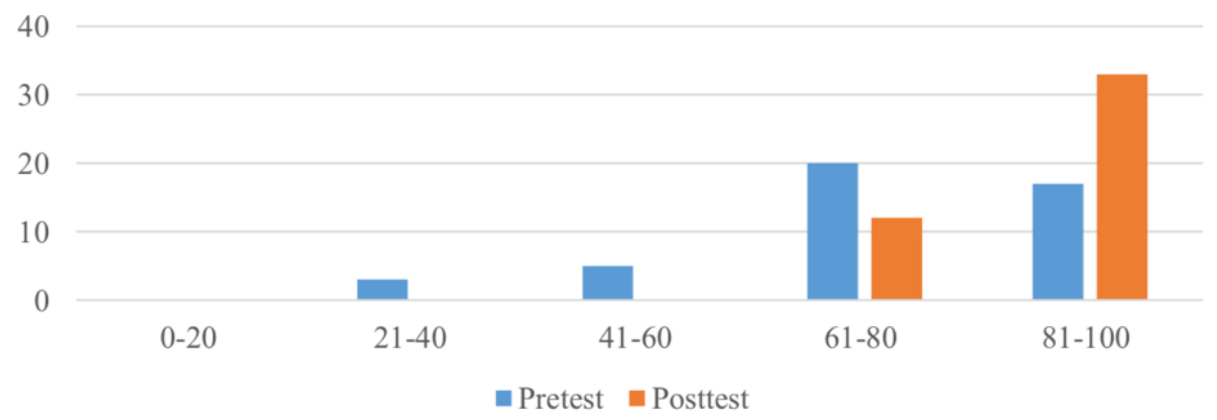

Fig. 2. Comparison of Pretest and Posttest Results

Based on the knowledge gain value from the respondents, the educational game that had been built has been able to become a learning medium to increase environmental awareness of the dangers of plastic waste among elementary students. Awareness of the environmental and the dangers of plastic waste was given through storylines, gameplay, and animated cutscenes packed into a strategy game. 


\subsection{Release}

The game "Plastic Stream" was released on itch.io which is a digital distribution service site for HTML5-based games, so other people can access the game through their browser and hopefully it will benefit them the way it benefits the students at Generasi Azkia Elementary School.

\section{Conclusion}

Plastic waste is a serious problem in Indonesia. Poor waste management and irresponsible behavior have caused plastic waste to pollute the soil and rivers, resulting in flooding in several parts of Indonesia. Plastic waste pollution also drifts in the oceans and threatens marine ecosystem. Changing behavior and awareness of the environment, as well as the dangers of plastic waste, need to start from childhood. An educational game to increase environmental awareness of the dangers of plastic waste had been developed in this study using the Game Development Life Cycle (GDLC) method which consists of six phases: initiation, pre-production, production, testing, beta, and release. From the results of beta testing, it was found that $71.11 \%$ of the primary school student respondents gained environmental knowledge. Based on the knowledge gain value from this research, the developed educational game is able to become a learning medium to increase awareness of the environment and the dangers of plastic waste among elementary students in Indonesia. Awareness of the environment and the dangers of plastic waste is given through storylines, gameplay, and animated cutscenes packed into a strategy game.

\section{$5 \quad$ References}

[1] Davis, H. (2015). "Life \& death in the Anthropocene: A short history of plastic," Art in the anthropocene: Encounters among aesthetics, politics, environments and epistemologies, 347-58. https://doi.org/10.26530/oapen_560010

[2] APME, An analysis of plastics production, demand and recovery in Europe. Brussels: Association of Plastics Manufacturers, 2016.

[3] Meikle, J. L. (1995).American Plastic: A Cultural History. New Brunswick, NJ: Rutgers University Press, 26.

[4] Thompson, R. C., Swan, S. H., Moore C. J. \& vom Saal, F. S. (2009). "Our plastic age," Philosophical transactions of the Royal Society of London. Series B, Biological sciences, 364(1526), 1973-1976. https://doi.org/10.1098/rstb.2009.0054

[5] Yarsley, V. E., Couzens, E. G. (2009). Plastics. Middlesex: Penguin Books Limited. 1945.

[6] Andrady A. L. \& Neal, M. A. "Applications and societal benefits of plastics," Philosophical transactions of the Royal Society of London. Series B, Biological sciences, 364(1526), 1977-1984. https://doi.org/10.1098/rstb.2008.0304

[7] Westermann, A. (2013). "The Material Politics of Vinyl: How the State, Industry and Citizens Created and Transformed West Germany's Consumer Democracy," in Accumulation: The Material Politics of Plastic, ed. Jennifer Gabrys, Gay Hawkins and Mike Michael, (London: Routledge), 76-77, 2013. https://doi.org/10.4324/9780203070215-13 
[8] Rochman, C., Browne, M. A., Halpern, B. S. et al, (2013). "Policy: Classify Plastic Waste as Hazardous," Nature 494 (14 February 2013): 169-171.

[9] Hopewell, J., Dvorak R. \& Kosior, E. (2009). "Plastics recycling: challenges and opportunities," Philosophical transactions of the Royal Society of London. Series B, Biological sciences, 364(1526), 2115-2126, 2009. https://doi.org/10.1098/rstb.2008.0311

[10] Barnes, D. K., Galgani, F., Thompson R. C. \& Barlaz, M. (2009). "Accumulation and fragmentation of plastic debris in global environments," Philosophical transactions of the Royal Society of London. Series B, Biological sciences, 364(1526), 1985-1998, 2009. https://doi.org/10.1098/rstb.2008.0205

[11] Gregory, M. R. (2009). "Environmental implications of plastic debris in marine settings-entanglement, ingestion, smothering, hangers-on, hitch-hiking and alien invasions," Philosophical transactions of the Royal Society of London. Series B, Biological sciences, 364(1526), 2013-2025. https://doi.org/10.1098/rstb.2008.0265

[12] Hammer, J., Kraak M. H. \& Parsons, J. R. (2012). "Plastics in the marine environment: the dark side of a modern gift," Rev Environ Contam Toxicol; 220:1-44, 2012. doi: 10.1007/978-1-4614-3414-6_1. PMID: 22610295.

[13] Jambeck, J. R., Geyer, R., Wilcox, C., Siegler, T. R., Perryman, M., Andrady, A., ... \& Law, K. L. (2015). Plastic waste inputs from land into the ocean. Science, 347(6223), 768771. https://doi.org/10.1126/science.1260352

[14] Triyanto \& H. Supriyono, Aplikasi Game Android Pengenalan Kebersihan Lingkungan untuk Anak Usia 6 - 7 Tahun. Undergraduate thesis, Universitas Muhammadiyah Surakarta, 2019.

[15] Baig, A., \& Alotaibi, A. (2020). Effect of Curriculum-Based Video Games on Students' Performance: An Experimental Study. International Journal of Emerging Technologies in Learning (iJET), 15(22), 244-257. https://doi.org/10.3991/ijet.v15i22.15541

[16] Castillo-Cuesta, L. (2020). Using Digital Games for Enhancing EFL Grammar and Vocabulary in Higher Education. International Journal of Emerging Technologies in Learning (iJET), 15(20), 116-129. https://doi.org/10.3991/ijet.v15i20.16159

[17] Meier, C., Saorín, J., de León, A. B., \& Cobos, A. G. (2020). Using the Roblox Video Game Engine for Creating Virtual tours and Learning about the Sculptural Heritage. International Journal of Emerging Technologies in Learning (iJET), 15(20), 268-280. https://doi.org/10.3991/ijet.v15i20.16535

[18] Adams, E. (2010). Fundamentals of game design, Second edition. New Riders, Pearson Education.

[19] Kanode, C. M., \& Haddad, H. M. (2009, April). Software engineering challenges in game development. In 2009 Sixth International Conference on Information Technology: New Generations (pp. 260-265). IEEE. https://doi.org/10.1109/itng.2009.74

[20] Ramadan, R., \& Widyani, Y. (2013, September). Game development life cycle guidelines. In 2013 International Conference on Advanced Computer Science and Information Systems (ICACSIS) (pp. 95-100). IEEE. https://doi.org/10.1109/icacsis.2013.6761558

[21] Rollings, A., \& Adams, E. (2003). Andrew Rollings and Ernest Adams on game design. New Riders. ISBN 1-59273-001-9.

[22] Foster, A. N. (2011). The process of learning in a simulation strategy game: Disciplinary knowledge construction. Journal of Educational Computing Research, 45(1), 1-27. https://doi.org/10.2190/ec.45.1.a

[23] Hake, R. R. (2002, August). Relationship of individual student normalized learning gains in mechanics with gender, high-school physics, and pretest scores on mathematics and spatial visualization. In Physics education research conference (Vol. 8, No. 1, pp. 1-14). 


\section{Authors}

Sheila Nurul Huda is a lecturer at Department of Informatics, Faculty of Industrial Technology, Universitas Islam Indonesia. Her research interests mainly focus on multimedia for education and informatics theory.

M. Fadillah Ramadhan is a former student at Department of Informatics, Faculty of Industrial Technology, Universitas Islam Indonesia, graduated in February 2021. His area of interest is in the field of educational game technology.

Article submitted 2021-03-15. Resubmitted 2021-04-21. Final acceptance 2021-04-24. Final version published as submitted by the authors. 